\title{
Edítorial.
}

\section{THE TEAGHING OF PSYGHOLOGIGAL MEDIGINE.}

T $T$ is more than a little surprising that despite the greatly increased interest in psychology that has developed in recent years, especially in the decade since the War, no corresponding change is evident in the curriculum laid down for the psychiatric training of medical students in this country. A perusal of the syllabuses of our medical schools shows that in most of them not only the courses prescribed, but the facilities offered, have increased but slightly in the last twenty years. There is still in most schools the brief course of a dozen or so systematic lectures, with a similar number of visits to an asylum for the purpose of clinical instruction ; but there is seldom any local ordinance (as there is no general one) compelling more than that. And the conditions under which the clinical teaching is done are not favourable; for in psychiatric clinical teaching alone is it the custom to have a class so unwieldy in numbers that to teach the individual student is an impossibility. The so-called clinical work seldom consists in more than a lecture at which some patients are presented. The general effect on the students is foreign to the spirit of medicine, and is more akin to the feeling induced by witnessing some curious spectacle.

Further, these courses, inadequate as they are (from no fault of the individual teacher) are given in the middle or towards the end of the clinical period. This is in spite of the fact that in the wards of any general hospital can be found psychological material, chiefly of the psychoneurotic, but often of the psychotic kind; and in disregard also of the seldom recognised but important circumstance that a large percentage of the patients in private practice consult their doctor for symptoms that have only the strong semblance of a physical origin. For the doctor whose eyes have been opened in this direction (and he is still a rare bird, for, as we have said, the subject cannot be held to be adequately taught in the schools) the percentage of such patients in his practice is high indeed. But more usually one hears the general practitioner remark in a half-apologetic way, "I see only one or two cases of this kind in a year." All 
the while the unqualified practitioner and the qualified man who can blind himself so far as to be enthusiastic in the use of some new-fangled panacea, are producing undoubted "cures," where the more orthodox practitioner has failed; and the forms of religion which lay their emphasis on bodily healing increase their adherents many-fold. Perhaps Medicine would have no ground for taking exception to this state of affairs, if such cures by such methods were the soundest that could by any means be obtained. But it is a first principle of medical practice to treat the disease rather than the symptoms; and there is little doubt that the practitioners and the cults alluded to treat merely the symptoms. Further, the spirit that inspires the progress of medicine works towards the increase of understanding; and these cults and practitioners do not trouble deeply to understand.

It is therefore a pity that when there exists a body of knowledge that is now as complete as that in most branches of medicine, it is not made available in the schools; for the courses in vogue there do not (as a rule) make it available. The student who is required to study pathology is first of all grounded in normal histology ; before he begins his bedside work he is taught physiology; but he is introduced to the clinical study of mental disorders (in most instances) before he knows any more of the mind than he might have picked up in desultory reading, or by commonsense. Nearly half of our medical schools offer preclinical courses in normal psychology; but only two or three of these make the course compulsory. Two or three schools at most offer any instruction in abnormal psychology. The case is far otherwise in the Dominions, where nearly every school of standing has a compulsory course of preclinical psychological work; and where frequently the prescribed clinical instruction is much more nearly adequate than it is with us. One Dominion university goes so far as to make psychiatry one of the four principal subjects of the final examination. In America, in the leading schools there, the medical student is introduced to the subject of psychology in his first year, and by means of lectures, demonstrations and individual work with patients, is never permitted to lose contact with the psychological aspects of medicine throughout all the years of his curriculum. Comparcd with these arrangements, what is provided in mcdical schools in this country (with a few conspicuous exceptions) is meagre indeed.

It is still a foremost principle of British Medicine to treat the patient as well as the disease. In so far as the practitioner 
obeys this principle, he is consciously or unconsciously using psychological methods. This is as it should be; but is it a departure from tradition to formulate the treatment on considered and established rules, with the fullest insight that scientific observation can give, rather than by rule of thumb?

If we were asked to formulate a scheme of psychiatric instruction, which, without being cumbrous and making a disproportionate demand on the already too much occupied medical curriculum, would yet furnish a satisfactory basis on which to construct experience, we would suggest something like the following.

A course of lectures on normal psychology (with some simple experimental work) in the same period as physiology is being studied, should be followed in the next year by a course of lectures on the principles of abnormal psychology, embellished wherever possible with clinical illustrations. The abnormal psychology so taught should be chiefly of the kind most likely to be useful to the student ; i.e., the types expounded by Dejerine, Meyer, and in this country by Ross. (The more recondite and less immediately useful parts of the Freudian psychology could safely be left to the specialists, or to individual curiosity). It is desirable that teaching in abnormal psychology should not be deferred till the late clinical period. It should form a ground- 8 work for the student who proceeds in one or other of his last two years to a clinical clerkship in an out-patient psychiatric department. The present statutory course in the principles and practice of psychological medicine would stand most conveniently in the fourth year, and according to the exigencies of the curriculum, clinical instruction at a recognised mental hospital could be given in this or in the final year. The latter should preferably be taken in the year in which the student is not acting as clinical clerk in an out-patient psychiatric department, thus ensuring that his clinical psychiatric interests shall be spread out over most of his general clinical period. It is at present Utopian to conceive the substitution for the usual clinical demonstration at a mental hospital, of clinical clerkships with the same type of material ; for this will be feasible only when psychiatric beds are provided in general hospitals, or when psychiatric clinics, such as nearly every university town in Germany possesses, are provided throughout this country. 